\title{
Nurse Communication
}

\section{About Goals of Care}

\author{
ELAINE WITTENBERG, ${ }^{1}$ PhD, BETTY FERRELL, ${ }^{1}$ RN, PhD, MA, FAAN, FPCN, CHPN, \\ JOY GOLDSMITH, ${ }^{2}$ PhD, HALEY BULLER, ${ }^{3} \mathrm{MS}$, and TAMMY NEIMAN, ${ }^{4} \mathrm{MS}, \mathrm{RN}-\mathrm{BC}$
}

\author{
From 'City of Hope National Medical Center, \\ Division of Nursing Research and Education, \\ Duarte, California, ${ }^{2}$ University of Memphis, Ten- \\ nessee, ${ }^{3}$ Chapman University, Orange, California, \\ 4St. Catherine University, St. Paul, Minnesota \\ Authors' disclosures of potential conflicts of \\ interest are found at the end of this article. \\ Correspondence to: Elaine Wittenberg, PhD, City \\ of Hope National Medical Center, Division of \\ Nursing Research and Education, 1500 E. Duarte \\ Road, Pop Sci Bldg 173, Duarte, CA 91010. \\ E-mail: ewittenberg@coh.org \\ doi: 10.6004/jadpro.2016.7.2.2 \\ (c) 2016 Harborside Press ${ }^{\circledast}$
}

\begin{abstract}
Conversations about goals of care with the patient and family are a critical component of advanced practice in oncology. However, there are often inadequate team structures, training, or resources available to assist advanced practitioners in initiating these conversations. We conducted a study to assess nurses' perceived role and communication tasks in such conversations about goals of care. In a cross-sectional survey of 109 nurses attending a comprehensive 2-day end-of-life nursing education course, nurses were asked to describe how they would participate in a "goals of care" meeting in three different scenarios. They were also asked what changes they desired in their clinical settings. Nurses overwhelmingly described that their primary task and communication role was to assess patient/family understanding. Nurses referenced their team members and team support with the least frequency across scenarios. Team roles, structure, and process were reported as areas in greatest need of change in patient/family goals of care meetings. These findings demonstrate that lack of preparation to function as a team is a barrier for nurses in communicating about goals of care, and there is a demand to move such conversations upstream in oncology care. J Adv Pract Oncol 2016;7:146-154
\end{abstract}

difficult conversation has been defined as an interaction between a provider and a patient at transition points on the disease trajectory (Svarovsky, 2013). In oncology, these transition points include sharing a new cancer diagnosis, deciding on treatment options, transitioning to survivorship, or shifting the focus to palliative care. These conversations, commonly known as "goals-of-care" discussions, often involve family and provide a platform for discussing and setting goals of care and sustaining hope by defining and reevaluating goals as the patient's disease progresses (Svarovsky, 2013). The conversations should trigger early discussions, educate the patient and family, be documented in the electronic medical record, and be evaluated based on performance standards 
(Bernacki, Block, \& American College of Physicians High Value Care Task Force, 2014).

Although goals-of-care conversations need to include trained advanced practitioners (APs) and target patients at high risk of death within the year, few APs have received formal communication training about these discussions, and hospital systems rarely have processes in place to ensure that these conversations take place. As a result, conversations about goals of care often occur too late to make a difference in the quality of care provided, patients are infrequently encouraged to actively participate in their own decision-making process, and often consent from the patient is implicit (Bélanger, Rodriguez, \& Groleau, 2011). This article summarizes the literature on goals-of-care conversations and presents a study on nurses' perception of these conversations.

\section{REVIEW OF THE LITERATURE}

Goals-of-care conversations often do not occur due to patient/family, provider, and system barriers. Patient/family barriers include difficulty accepting a poor prognosis, difficulty in understanding complications of life-sustaining treatments, disagreement among family members, and the patient's incapacity to participate in these important discussions (You et al., 2015). Provider barriers include insufficient knowledge about the patient, inconsistent assessment of the patient's nonmedical goals, and failure to provide sufficient information for decision-making (Bernacki et al., 2014). Systemic barriers include obstacles to team communication, especially for sharing information across services and between specialties, with variation in documentation systems delaying workflow and care coordination (McCorkle et al., 2012). Advanced practitioners experience role tension due to the variability across disease teams and between inpatient and outpatient settings, which can create a disparity in team communication and impede coordination (McCorkle et al., 2012).

Despite these barriers, goals-of-care conversations remain a gold standard in facilitating patient-centered communication and shared decision-making (Bakitas, Kryworuchko, Matlock, \& Volandes, 2011; Tamburro, Shaffer, Hahnlen, Felker, \& Ceneviva, 2011). Shared decision-making is a process often characterized by patient-family-provider involvement, information sharing between parties, acknowledgment of all preferences, and agreement over future plans (Charles, Gafni, \& Whelan, 1997; Moumjid, Gafni, Brémond, \& Carrère, 2007). Shared decision-making is inhibited by unmet information needs and unrealistic expectations, the framing of options in consultations, and the patient's/family's wish to delay decisions to follow default patterns of care (Bélanger et al., 2011).

Although little is known about the impact of participation in decision-making, researchers have found that lower levels of health literacy have the potential to negatively influence patient participation (McCaffery et al., 2013). Health literacy is defined as an individual's capacity to obtain, process, and understand basic health information and is often regarded as a highly important factor in patient-provider interactions (The Patient Protection and Affordable Care Act, 2010).

However, those individuals who are less health-literate often have more issues relating to successful patient-provider interactions. For instance, lower health literacy is associated with lower patient health knowledge (McCaffery et al., 2013) and with higher decisional uncertainty and regret. Low patient health knowledge and decisional uncertainty, if overlooked by the healthcare team, can result in negative consequences such as miscommunication (Kawachi \& Kennedy, 1997). In addition, individuals with lower health literacy often have less desire for involvement, ask fewer questions, and experience less patient-centered care (McCaffery et al., 2013). All of these factors could potentially influence patient and family participation in the shared decision-making process, which can be detrimental to the overall quality of any goals-of-care conversations.

Decision support tools such as brochures, audiovisual materials, educational sessions, counseling sessions, and interactive websites or media have been implemented to improve goals-of-care conversations and encourage participation in decision-making ( $\mathrm{Wu}$, Boushey, Potter, \& Stacey, 2014); however, most of these tools are patientfocused rather than patient- and family-focused. This is problematic given the increasing reliance on family caregivers for assistance with care, 
transportation to appointments, and involvement in decision-making as proxy. Although family involvement is not necessary in every case, many families have reported feeling misunderstood or neglected when their involvement in the patient's care is not considered (Elwyn et al., 2013b).

Although support tools have been developed, most of the patient decision aids are for independent use either before or after clinical visits (Elwyn et al., 2013a), and widespread adoption of these decision-support interventions has not yet occurred (Elwyn et al., 2013b). Further, few of these tools include decision-coaching, and many neglect to assess communication in the encounter (Elwyn et al., 2013b). Most decision tools are never fully implemented by providers due to time pressures, and providers often perceive a lack of applicability to patient characteristics or clinical situations (Wu et al., 2014).

Research and communication skills training about goals-of-care conversations are also heavily physician-focused (Svarovsky, 2013), neglecting the role of the AP (Elwyn et al., 2013b). Although patients do not express uniform agreement about which clinician they prefer for goalsof-care conversations (Bernacki et al., 2014), a variety of health-care providers have concluded that advanced practice nurses or social workers would be excellent providers for initiating such discussions and decision-coaching (You et al., 2015). Advanced practice nurses are expected to support decision-making by providing information, conveying empathy and building trust, and advocating to others about the patient's wishes (Adams, Bailey, Anderson, \& Docherty, 2011), yet there is little instruction available for them about how to communicate in a way that accomplishes this approach (Elwyn, Frosch, Volandes, Edwards, \& Montori, 2010).

Nurses are expected to consider the patient's values and quality-of-life preferences and to review them with the patient and family in a manner separate from their own daily goals and treatment tasks (Martin \& Koesel, 2010). Given the emphasis on nurse communication skills to determine the goals and preferences of patients and families and assist with health-care decision-making (National Consensus Project for Quality Palliative Care, 2013), this study explored nurses' perception of their role and communication tasks during goalsof-care conversations with patients and family in three different contexts.

\section{METHODS}

An open-ended survey was distributed to nurses attending one of four End-of-Life Nursing Education Consortium (ELNEC) programs. These ELNEC programs are delivered in a 2-day train-the-trainer format, providing participants with comprehensive curriculum about end-of-life care including communication. Nurses voluntarily completed the survey prior to receiving course content. The survey was determined to be exempt under the institutional review board at the supporting institution.

\section{Instrument}

Consisting of four open-ended items, the survey was developed by nursing, communication, and oncology research experts. Nurses were presented with three different oncology case scenarios and asked to describe how they would participate in a goals-of-care meeting involving (1) the health-care team, patient, and family; (2) a patient, following physician disclosure of lifealtering information; and (3) when a patient asks to talk about treatment decisions (Table 1). To assess areas for improvement, a final open-ended question invited nurses to describe what changes were needed for goals-of-care conversations in their current position or setting.

\section{Data Analysis}

A research team member transcribed all open-ended responses, and three members of the research team reviewed them. Inductive-content analysis was used in two phases (Elo \& Kyngäs, 2008). First, each research team member individually conducted open coding by identifying unrestricted chunks of text and creating categories. Second, research team members met to integrate categories and come to consensus by discussing independently created identified themes and connecting, collapsing, or associating to establish categories. Identification of categories emerged from strong representation throughout responses and was verified by coding and frequency calculation. 


\section{Table 1. Open-Ended Survey Scenarios Regarding Goals-of-Care Conversations}

- Elderly man with bladder cancer

Diagnosed with bladder cancer, Giuseppe is a 91-yearold Italian man and a devout Catholic. His condition is declining rapidly, and he is admitted monthly to the hospital for blood transfusions. He doesn't understand a lot about the cancer, but he does know that the tumors keep coming back and are what are causing his condition. The family doesn't want to tell him that he has cancer; although they don't keep anything from him, they just don't use the word "cancer" when talking about his illness.

During your team's meeting with Giuseppe and his family to discuss goals of his care, what ways do you personally participate and help Giuseppe and his family make decisions about his care?

- War veteran with lung cancer

As part of a visit with Thomas, a veteran of the Vietnam War, his physician explains that there are no treatment options left that will cure his lung cancer. From your own assessment, you know that Thomas is a widower and has no children. Soon after sharing this news, the physician

leaves, and you are alone with the patient.

How and what do you communicate with Thomas to help him make decisions about his care?

- Young woman with breast cancer

Blythe is a 35-year-old married woman with 3 children ages 2, 3, and 7 . She has been diagnosed with stage 2 breast cancer and does not have a history of breast cancer in her family. She is not from the area, and her husband works out of the state 3 out of 4 weeks a month. Her oncologist has recommended a rigorous regimen of radiation and chemotherapy. Blythe asks you to talk with her about her treatment decisions.

How and what do you communicate with Blythe to help her make treatment decisions?

\section{RESULTS}

\section{Study Participants}

A total of 193 nurses were surveyed, with 109 completing the open-ended items of the survey. Half of the nurses surveyed had more than 16 years of nursing experience. They came from a variety of settings, most commonly hospital (50\%) and university (25\%) settings. Table 2 summarizes the participant demographics.

Participants overwhelmingly described assessing patient understanding as the dominant goal-of-care communication. Across all three scenarios, the nurses' primary response was first to assess patient and/ or family understanding of the disease and prognosis and ask questions about the patient's goals of care.

\section{Table 2. Overview of Participant Demographics $(N=109)$

Characteristic N (\%) \\ Geographic region \\ Northeast (CT, ME, MA, NH, NJ, NY, PA, 24 (22\%) \\ VT) \\ Midwest (IL, IN, IA, KS, MI, MO, NE, OH, 24 (22\%) $\mathrm{SD}, \mathrm{WI})$ \\ South (FL, GA, MD, MS, NC, OK, SC, TN, 36 (33\%) $T X, V A, D C$ ) \\ West (AK, AZ, CA, CO, MT, NV, OR, UT) 23 (21\%) \\ Ontario, Canada \\ Not reported \\ Years of experience \\ $<1$ year \\ $11(10 \%)$ \\ 1-5 years \\ 15 (14\%) \\ 6-10 years \\ $12(11 \%)$ \\ 11-15 years \\ 17 (15\%) \\ $\geq 16$ years \\ $54(50 \%)$}

Type of institution*

Home care

$10(9 \%)$

Hospice

$16(15 \%)$

Outpatient/ambulatory care

$20(18 \%)$

University/school of nursing

$27(25 \%)$

Hospital

$54(50 \%)$

Other

$12(11 \%)$
The highest frequency of this communication task $(n=65)$ appeared in response to the third scenario, in which a patient requested a discussion with the nurse about treatment decisions. The second most common communication task/role in each of the three scenarios reflected the circumstances of each scenario.

The first scenario depicted team members present and nurses focusing attention on family $(n=42)$ as their key role (Table 3$)$. In scenario two, following physician disclosure of a poor prognosis, nurses emphasized being present with the patient (Table 4 ) by describing listening $(n=56)$. In the third scenario, when asked by the patient about treatment decisions, nurses described in- 


\section{Table 3. Nurse Responses for Goals-of-Care Meeting With Health-Care Team, Patient, and Family}

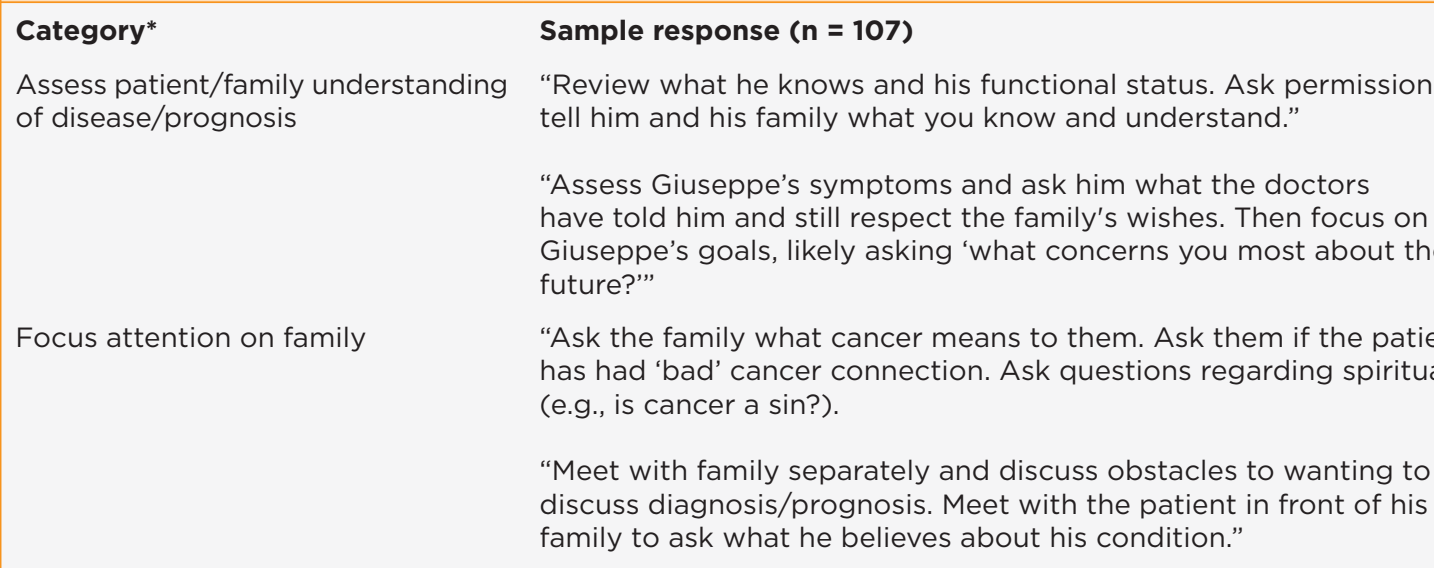

Discuss psychosocial topics, such as spirituality and fears

"Ask what is most important to them. Ask what they fear the most."

"What are the gifts of his life? Does he have goals or things that he wants to achieve? What role does family and faith play in his life? How has his illness affected the quality of his life/functional states?"

Seek team support, referrals to

"Ask the social worker, the chaplain, as well as the oncologist (if there is one available) to be part of the discussion. Write up (on a board, easel, etc.) the salient concerns expressed and options for care moving forward."

Initiate end-of-life topics (advance directives, hospice, pain

"Talk about his illness, not cancer. Discuss treatment, not chemotherapy. Focus on symptom management and quality of life." symptom management, and quality of life."

Note. ${ }^{*}$ Categories not mutually exclusive.

quiring about patient resources concerning care, side-effect tolerance, and place of care $(n=57)$ and reported that they would assess for understanding and also convey information honestly (Table 5).

Overall, participant comments showed little difference in approach to goals-of-care conversations and communicative tasks, despite the different scenarios presented. In none of the three scenarios were team members or support from other disciplines identified frequently, and in fact team members and team support was the least mentioned communication task/role element across all scenarios.

Finally, an open-ended question offered nurses an opportunity to share what they wished was different about goals-of-care communication in their work setting. In terms of needing change, nurses overwhelmingly pointed to team roles, structures, and processes as the areas of change needed to improve such communication (Table 6). These two findings (low frequency in scenarios and high fre- quency in desired changes) are in consonance with one another. Closely related to team structures and processes, nurses commonly described the need and desire for goals-of-care conversations to occur earlier in the cancer care continuum.

\section{DISCUSSION}

This study provides unique findings about nurse perceptions of their role and communication tasks during goals-of-care conversations across three oncology care scenarios. Additionally, nurses identified desired changes in goals-of-care communication in their own settings. As the sample in this study had extensive clinical experience, their task and role perceptions as well as challenges represent experiential credibility, strengthening these findings.

Overall, the dominating nurse response to goals-of-care tasks was representative of nursing education to assess patient understanding. Recent 


\section{Table 4. Nurse Responses Following Physician Disclosure of a Poor Prognosis and Exit}

\section{Category*}

Assess patient understanding; ask questions about goals of care

Be present, listen to patient process feelings

Inquire about patient's support network, available resources

Seek team support

\section{Sample response $(n=107)$}

"Ask Thomas if there is anyone in his life he would like to be a part of his care. Ask him to explain what he thinks the physician meant and what it means for him. Ask him what he foresees his needs being. What does he want?"

"Great start to the conversation would be, "What do you understand about what was just described by the oncologist?",

"Open conversation with a caring statement such as, 'What are you thinking or feeling right now?' Let the patient talk and listen."

"Find out who (if anyone) he would want involved in decisionmaking/proxy."

"Ask about his wishes. Who helps him make decisions? What are his support options? Does he have a power of attorney or a will?"

"Who does he turn to and trust? Who could help him? How can I help? Who could make decisions if he cannot?"

"Have a social worker involved in the planning and support process, and facilitate contacting the people in his life who may be helpful (with his permission). I would also contact his primary care physician with the information and offer to assist with ongoing transitions of care."

"Call in social work to help."

"Refer to social worker and/or spiritual coordinator, depending on his concerns."

\section{n (\%)}

$56(52 \%)$

Note. ${ }^{*}$ Categories not mutually exclusive.

\section{Table 5. Nurse Responses When a Patient Asks to Talk About Treatment Decisions}

\section{Category*}

Assess patient understanding, ask about goals of care, research treatment options, outline risk-benefit ratios

Inquire about patient's support network, available resources

Communicate honestly and encourage patient to lead conversation, describe typical day of treatment

Seek team support, make specific referrals for team support

\section{Sample response $(n=102)$}

n (\%)

"Find out from Blythe exactly what she was told about her condition first."

$65(63 \%)$

"Discuss risks vs. benefits of recommended treatment interventions (collaborate). Discuss quality of care, need for supportive care, resources available (patient never alone with cancer). Discuss code."

"It's important she choose a treatment plan that will work with her family and discuss what type of extended family/friend support system she has."

"Acknowledge difficulty. Explore her feelings and thoughts and offer a presence. Go where the patient's thoughts are."

"Start with her concerns. Is there anyone who can help?"

"Confirm with physician what treatment options are to best educate the patient. Involve social worker and an care needs."

Note. ${ }^{*}$ Categories not mutually exclusive. 


\section{Table 6. Nurse-Desired Changes in Goals-of-Care Conversations in Current Setting}

\begin{tabular}{|c|c|c|}
\hline Category & Sample response $(n=103)$ & n (\%) \\
\hline \multirow[t]{4}{*}{ Team roles, structures, and processes } & $\begin{array}{l}\text { "Clearer lines of communication about who leads meeting } \\
\text { outside of palliative medicine unit." }\end{array}$ & $43(42 \%)$ \\
\hline & $\begin{array}{l}\text { "News delivered by an interdisciplinary team (planned } \\
\text { meeting) rather than a fragmented delivery." }\end{array}$ & \\
\hline & $\begin{array}{l}\text { "Written completed goals shared with the whole team. Full } \\
\text { documentation and transparency." }\end{array}$ & \\
\hline & $\begin{array}{l}\text { "The belief by our palliative MDs that they are the 'experts' } \\
\text { and no one else does it well." }\end{array}$ & \\
\hline \multirow[t]{2}{*}{ Earlier goals-of-care conversations } & $\begin{array}{l}\text { "Usually, my experience is that there is zero communication } \\
\text { with primary care physicians regarding goals of care, and the } \\
\text { oncologist is telling the patient 'we are going to do XYZ.' The } \\
\text { patient often does not know that there is a goal other than } \\
\text { cure and often thinks a cure is possible, even with stage } 4 \\
\text { and metastases." }\end{array}$ & $26(26 \%)$ \\
\hline & $\begin{array}{l}\text { "They happen earlier vs. when the patient and/or family is in } \\
\text { crisis." }\end{array}$ & \\
\hline \multirow[t]{2}{*}{$\begin{array}{l}\text { Resource needs, including time, } \\
\text { space, and administrative support }\end{array}$} & $\begin{array}{l}\text { "I wish we had more time. Our service is becoming busy, and } \\
\text { we have limited providers for big numbers of consults due to } \\
\text { budget restraints." }\end{array}$ & $17(17 \%)$ \\
\hline & $\begin{array}{l}\text { "We do not have enough conference rooms (meet with } \\
\text { families in the nurse locker rooms at times)." }\end{array}$ & \\
\hline \multirow{2}{*}{$\begin{array}{l}\text { Communication training needs for } \\
\text { disclosure, meetings, access to } \\
\text { patient/family information }\end{array}$} & $\begin{array}{l}\text { "The people generally having them are not trained in this } \\
\text { area." }\end{array}$ & $16(16 \%)$ \\
\hline & $\begin{array}{l}\text { "More honesty and transparency about a patient's } \\
\text { prognosis." }\end{array}$ & \\
\hline
\end{tabular}

work has shown that years of nursing experience is positively associated with comfort in communicating about end of life, one of the transition points in a goals-of-care discussion (Moir, Roberts, Martz, Perry, \& Tivis, 2015).

Still, nurses experience unclear team roles when providing palliative care to patients/families (Beckstrand, Collette, Callister, \& Luthy, 2012; Klarare, Hagelin, Fürst, \& Fossum, 2013). Palliative care communication is a unique skill that nurses engage in across care settings and throughout the disease trajectory (Goldsmith, Ferrell, Wittenberg Lyles, \& Ragan, 2013; Malloy, Virani, Kelly, \& Munevar, 2010). There is little question that nurses have distinctive needs and demands in their goals-of-care communication and should be educated to handle the communication demands placed upon them.

Although assessing patient understanding is a key focus of goals-of-care conversations, there is also a general consensus that these conversations should include providing the prognosis and discussing acceptable trade-offs and function for the patient
(Bernacki et al., 2014). Patient preferences for goals of care often include statements about length of life, symptom control, and preferred location for living or dying (Gramling et al., 2015). Similar research concluded that communication strategies for goalsof-care conversations include describing the signs that indicate a transition in care is approaching and explicitly stating when a patient or family stated goal is not clinically feasible (Norton et al., 2013).

However, findings from this study depict a different scope and role for APs, demonstrating an emphasis on patient understanding and family support rather than delivering or discussing prognosis. The content of goals-of-care conversations for APs may vary depending on the health-care team, clinical setting, and patient/ family understanding. The minimal presence of team in goals-of-care communication may indicate the need to clarify how a team can address goals of care and improve team function when serving patients and families. Future work is needed to determine team-based preferences for the AP's role in these conversations. 
One of the limitations of this study is the sample's presence at an educational training session for end-of-life nursing practice. The providers attending had experience and knowledge of goals-of-care communication not typical of other nursing specialists and practitioners. Perspectives from nurses in different clinical settings should be studied in future research.

The lack of a formal review process to evaluate performance in goals-of-care conversations further impedes professional growth in the area of communication skills development (McCorkle et al., 2012). Future studies need to evaluate interventions to improve communication and shared decision-making (Kryworuchko, Hill, Murray, Stacey, \& Fergusson, 2013). Further research on option grids, which are a tool to help patients compare alternative treatment options, showed early promise for patient engagement in decision-making in partnership with providers (Elwyn et al., 2013a).

\section{CONCLUSION}

This study demonstrates that nurses perceive primary communication in goals of care to focus on the task of assessing patient understanding. Nurses reported that their most frequent concerns over goalsof-care communication were the function, structure, and process of the care team. Findings demonstrate that preparation to function as a team in the context of goals-of-care communication is a barrier for nurse participants, and they report a need to move goals of care upstream in the care provided to patients and their families. Future research should explore patient and family expectations of nurses and teams during goals-of-care conversations to shape education and curricular development for the next wave of palliative care providers.

The study has important implications for APs in oncology. These providers are the ones who discuss initial diagnosis and treatment options as well as prognosis with patients. They are also facilitators of advanced-care planning, team meetings, and family conferences. Each of these roles has a strong impact on quality patient care and family support.

\section{Disclosure}

The authors have no potential conflicts of interest to disclose.

\section{References}

Adams, J. A., Bailey, D. E., Jr., Anderson, R. A., \& Docherty, S. L. (2011). Nursing roles and strategies in end-of-life decision making in acute care: A systematic review of the literature. Nurse Research and Practice, 2011, 527834. http://dx.doi.org/10.1155/2011/527834

Bakitas, M., Kryworuchko, J., Matlock, D. D., \& Volandes, A. E. (2011). Palliative medicine and decision science: The critical need for a shared agenda to foster informed patient choice in serious illness. Journal of Palliative Medicine, 14(10), 1109-1116. http://dx.doi.org/10.1089/ jpm.2011.0032

Beckstrand, R. L., Collette, J., Callister, L., \& Luthy, K. E. (2012). Oncology nurses' obstacles and supportive behaviors in end-of-life care: Providing vital family care. Oncology Nursing Forum, 39(5), E398-E406. http:// dx.doi.org/10.1188/12.ONF.E398-E406

Bélanger, E., Rodriguez, C., \& Groleau, D. (2011). Shared decision-making in palliative care: A systematic mixed studies review using narrative synthesis. Palliative Medicine, 25(3), 242-261. http://dx.doi. org/10.1177/0269216310389348

Bernacki, R. E., Block, S. D., \& American College of Physicians High Value Care Task Force. (2014). Communication about serious illness care goals: A review and synthesis of best practices. JAMA Internal Medicine, 174(12), 1994-2003. http://dx.doi.org/10.1001/jamainternmed.2014.5271

Charles, C., Gafni, A., \& Whelan, T. (1997). Shared decisionmaking in the medical encounter: What does it mean? (or it takes at least two to tango). Social Science $\mathcal{E}$ Medicine, 44(5), 681-692. http://dx.doi.org/10.1016/S02779536(96)00221-3

Elo, S., \& Kyngäs, H. (2008). The qualitative content analysis process. Journal of Advanced Nursing, 62(1), 107-115. http://dx.doi.org/10.1111/j.1365-2648.2007.04569.x

Elwyn, G., Frosch, D., Volandes, A. E., Edwards, A., \& Montori, V. M. (2010). Investing in deliberation: A definition and classification of decision support interventions for people facing difficult health decisions. Medical Decision Making, 30(6), 701-711. http://dx.doi. org/10.1177/0272989X10386231

Elwyn, G., Lloyd, A., Joseph-Williams, N., Cording, E., Thomson, R., Durand, M. A., \& Edwards, A. (2013a). Option grids: Shared decision making made easier. Patient Education and Counseling, 90(2), 207-212. http://dx.doi. org/10.1016/j.pec.2012.06.036

Elwyn, G., Scholl, I., Tietbohl, C., Mann, M., Edwards, A. G., Clay, C.,...Frosch, D. L. (2013b). "Many miles to go...": A systematic review of the implementation of patient decision support interventions into routine clinical practice. BMC Medical Informatics and Decision Making, 13(suppl 2), S14. http://dx.doi.org/10.1186/1472-6947-13-S2-S14

Goldsmith, J, Ferrell, B., Wittenberg-Lyles, E., \& Ragan, S. L. (2013). Palliative care communication in oncology nursing. Clinical Journal of Oncology Nursing, 17(2), 163-167. http://dx.doi.org/10.1188/13.CJON.163-167

Gramling, R., Sanders, M., Ladwig, S., Norton, S. A., Epstein, R., \& Alexander, S. C. (2015). Goal communication in palliative care decision-making consultations. Journal of Pain and Symptom Management, 50(5), 701-706. http:// dx.doi.org/10.1016/j.jpainsymman.2015.05.007

Kawachi, I., \& Kennedy, B. P. (1997). Health and social cohe- 
sion: Why care about income inequality? BMJ, 314(7086), 1037-1040. http://dx.doi.org/10.1136/bmj.314.7086.1037

Klarare, A., Hagelin, C. L., Fürst, C. J., \& Fossum, B. (2013). Team interactions in specialized palliative care teams: A qualitative study. Journal of Palliative Medicine, 16(9), 1062-1069. http://dx.doi.org/10.1089/jpm.2012.0622

Kryworuchko, J., Hill, E., Murray, M. A., Stacey, D., \& Fergusson, D. A. (2013). Interventions for shared decision-making about life support in the intensive care unit: A systematic review. Worldviews on Evidence Based Nursing, 10(1), 3-16. http://dx.doi.org/10.1111/j.1741-6787.2012.00247.x

Malloy, P., Virani, R., Kelly, K., \& Munevar, C. (2010). Beyond bad news: Communication skills of nurses in palliative care. Journal of Hospice \& Palliative Nursing, 12(3), 166174. http://dx.doi.org/10.1097/NJH.0b013e3181d99fee

Martin, B., \& Koesel, N. (2010). Nurses' role in clarifying goals in the intensive care unit. Critical Care Nurse, 30(3), 6473. http://dx.doi.org/10.4037/cen2010511

McCaffery, K. J., Holmes-Rovner, M., Smith, S. K., Rovner, D., Nutbeam, D., Clayman, M. L.,...Sheridan, S. L. (2013). Addressing health literacy in patient decision aids. BMC Medical Informatics and Decision Making, 13(suppl 2), S10. http://dx.doi.org/10.1186/1472-6947-13-S2-S10

McCorkle, R., Engelking, C., Knobf, M. T., Lazenby, M., Davies, M., Sipples, R.,...Lyons, C. (2012). Transition to a new cancer care delivery system: Opportunity for empowerment of the role of the advanced practice provider. Journal of the Advanced Practitioner in Oncology, 3(1), 34-42. http://dx.doi.org/10.6004/jadpro.2012.3.1.4

Moir, C., Roberts, R., Martz, K., Perry, J., \& Tivis, L. J. (2015). Communicating with patients and their families about palliative and end-of-life care: Comfort and educational needs of nurses. International Journal of Palliative Nursing, 21(3), 109-112. http://dx.doi.org/10.12968/ ijpn.2015.21.3.109

Moumjid, N., Gafni, A., Brémond, A., \& Carrère, M. O.
(2007). Shared decision making in the medical encounter: Are we all talking about the same thing? Medical Decision Making, 27(5), 539-546. http://dx.doi. org/10.1177/0272989X07306779

National Consensus Project for Quality Palliative Care. (2013). Clinical Practice Guidelines for Quality Palliative Care (3rd Ed.). Retrieved from http://www.nationalconsensusproject.org

Norton, S. A., Metzger, M., DeLuca, J., Alexander, S. C., Quill, T. E., \& Gramling, R. (2013). Palliative care communication: Linking patients' prognoses, values, and goals of care. Research in Nursing \& Health, 36(6), 582-590. http://dx.doi.org/10.1002/nur.21563

The Patient Protection and Affordable Care Act, 42 U.S.C. 9 18001. (2010). Retrieved from https://www.gpo.gov/fdsys/pkg/PLAW-11lpubl148/html/PLAW-111publ148.htm

Svarovsky, T. (2013). Having difficult conversations: The advanced practitioner's role. Journal of the Advanced Practitioner in Oncology, 4(1), 47-52. http://dx.doi. org/10.6004/jadpro.2013.4.1.5

Tamburro, R. F., Shaffer, M. L., Hahnlen, N. C., Felker, P., \& Ceneviva, G. D. (2011). Care goals and decisions for children referred to a pediatric palliative care program. Journal of Palliative Medicine, 14(5), 607-613. http:// dx.doi.org/10.1089/jpm.2010.0450

Wu, R., Boushey, R., Potter, B., \& Stacey, D. (2014). The evaluation of a rectal cancer decision aid and the factors influencing its implementation in clinical practice. $B M C$ Surgery, 14, 16. http://dx.doi.org/10.1186/1471-2482-14-16

You, J. J., Downar, J., Fowler, R. A., Lamontagne, F., Ma, I. W., Jayaraman, D.,...Canadian Researchers at the End of Life Network. (2015). Barriers to goals of care discussions with seriously ill hospitalized patients and their families: A multicenter survey of clinicians. JAMA Internal Medicine, 175(4), 549-556. http://dx.doi.org/10.1001/jamainternmed.2014.7732 